\title{
Questions and Answers Session V
}

\section{Frederick Friend}

I would like to note the work of the Open Society Institute, which is behind the Budapest Initiative. The Open Society Institute is trying to help developing countries in a variety of ways. For example, by negotiating national licences for access to journals, and by training. I agree with Barbara Aronson on the need to listen to the developing countries. We have learnt to do this at the Open Society Institute. For example, we held a recent meeting attended by librarians from a number of African countries. We were talking to them about national purchasing. However, they told us that what they really needed was assistance with their infrastructure. We had not really seen that as being our role. However, it is only in listening to people that you find out their real needs.

\section{Stevan Harnad}

Six months ago at the American Scientists Forum, Barbara Kirsop questioned, on behalf of the developing world, the wisdom of licensing the Eprint software to Ingenta. Also, in relation to the question of whether the needs of Southern countries are more focused on Southern access to Northern literature or greater visibility in the North of the Southern literature, Barbara Kirsop suggested that visibility of Southern literature in the North was the primary need. In contrast, Barbara Aronson's questionnaire suggests that Southern access to Northern literature was the paramount goal. If the latter is the case, there is not a great deal that can be done directly by the South. However, if the former is the case, the South can lead the developments.

\section{Barbara Kirsop}

No, I did not say that the primary need was for visibility of South research in the North. When asked, I passed the question to our colleagues in the developing world, I obtained the impression that it was a very Northern question to ask. The Southern answer was that they needed both, equally. We cannot make a distinction between the two: everything is important when you are starting from a low base (i.e. nothing). As has been said already, we must ask the developing world for answers, but it is necessary that respondents to questionnaires are fully informed of all the options available to them.

\section{Barbara Aronson}

I can only report on the health sector. The WHO received 1100 responses to its questionnaire that was sent to about 130 developing countries. A follow up meeting was held to discuss the results of the questionnaire with 90 researchers from developing countries.

During the session devoted to information, which was extremely popular, three needs were identified. First, researchers from developing countries want access to the priced literature. Second, they want to be recognised internationally in the leading journals. Scientists from developing countries do not need to publish in order to advance in their own institutions, but they desperately need international recognition in order to obtain research funding. Third, they want to have the concept of duplicate publication (in international and in local journals) approved. That is, they work mainly on applied research in the medical world. They are the only ones carrying out this research on diseases that often the developed world does not suffer from. This results in a real problem. In order to secure funding and continue their research, 
they have to publish internationally. However, if they publish internationally, the people who need access to the results of their research will not be able to gain access. Duplicate publishing could address this dilemma.

We then asked them to set priorities among the three needs. By far, their top priority was access to the priced literature. We have done that and we are now working on improving the quality and distribution of the research writing coming out of the developing countries. In relation to duplication of research in international and local journals, an immediate solution lies in open access.

Ingenta works with us on HINARI because many of the HINARI publishers have their journals on Ingenta. If Ingenta would accept the HINARI pricing framework, that would solve the problem. While nothing can be done without incurring costs, those costs should be borne by those who can afford to do so. They should not be levied on those who cannot afford them.

\section{Jean-Claude Guedon}

In Africa the cost of access to Internet is extremely high. Barbara Aronson quoted a figure of USD 4 per minute. In this context, a meeting of ministers was held on the information highway in 1997 in Montreal at which I stated that we absolutely had to solve the bandwidth problem. The Swiss representative replied that infrastructure issues were part of the bilateral and not the multilateral domain. Countries that have economic interests in Africa want to preserve their economic interests in the communications industry. We thus have a situation where African countries are paying USD 4 per minute while at the same time we have a bandwidth glut in North America. Something needs to be done to resolve this situation. In order for training to be effective, we first need to create and improve infrastructures. Some type of open access to infrastructures is crucial to all of these issues.

\section{Geoffrey Bilder}

In relation to the question of pricing and Ingenta, it should be noted that Ingenta does not set pricing. Rather, the publishers do. However, Ingenta provides many publishers with a common mechanism for setting that pricing. A practical approach would be for HINARI to talk with Ingenta with a view to setting up a mechanism that allows them to opt in or out of a pricing scheme. Of course, access control would then be an item to be looked at.

\section{Francis Muguet}

Open access journals are the only technical solution possible to set up mirrors in universities in the Third World. Open access is thus the only technical way to allow the complete download of the content of journals being mirrored in the universities in these countries.

\section{Geoffrey Bilder}

A further issue beyond pricing that needs to be resolved is connectivity. We have been looking at a number of ways to allow us to co-locate Ingenta locally.

\section{Yahia Bakelli}

As a researcher from the developing world, I have been working in Algeria on the issues of visibility of local content since 1995. The lesson I have drawn from my experience in this area is that obtaining the involvement of researchers from the Third World is a very complex task involving technical and economic aspects. Improving the connectivity platform is readily possible in technical terms. However, the main outstanding issue is to be found at the social cultural level. Researchers in the South argue that they are less interested in having their work published in the North. Instead, their main concern is access to Northern journals. It is necessary to change this mentality by involving Southern researchers in 
international networks by focusing on the globalisation of science and promoting science at the global level. This requires researchers in the North to welcome and facilitate our tasks.

\section{David Prosser}

Are you also promoting access to the free online journals? It would be a pity if researchers in developing countries were not made aware of the fact that they already have access to these journals, such as BioMed Central.

\section{Barbara Aronson}

Yes, we are promoting access to the free online journals. BioMed Central is a partner of HINARI's, and is making its priced journals available through HINARI. Links to all the sites for free medical books and journals are included on the HINARI menu in a special section that draws attention to them.

\section{Manfred Spiesberger}

We also provide links and information on free resources on our web page and the e-library web pages of our two subcontractors. In relation to the issue of infrastructure, which is quite important, we try to cooperate with institutions that are active in this area in order to optimise the implementation of our actions. We cooperate for example with the NATO Science programme, which is establishing fast internet connection via satellite for the Central Asian and Caucasus countries.

\section{Barbara Kirsop}

Many of the publications available through Bioline International are already free. Some publishers from developing countries have stopped charging for their online journals as they have realised that increasing their visibility is much more important. Bioline International has also set up an e-print server at the University of Toronto and is working with publishers from developing countries to use this or even set up their own e-print servers. There is thus a slow migration from traditional sources towards e-print servers.

\section{Jean-Jacques Pierrat}

In relation to infrastructure, one of the priorities of our Ministry is the reduction of cost. It is both a political priority and a priority in the actions we carry out. I would say that the access cost mentioned earlier of EUR 4 per minute is not correct. I have visited and lived in a number of African countries and would argue that the costs are lower than this.

As well as infrastructure, content is also a priority. Ghana is currently installing the necessary infrastructure in partnership with a number of donors. However, the researchers I spoke to expressed their concerns in relation to the future: once the donors withdraw, these tools will become very expensive to operate. They are therefore interested in placing content onto these servers. This represents the second phase of development for these countries.

I earlier mentioned a project related to biodiversity. What is important here is that the biodiversity databases are currently located in the North. Researchers in the South who are interested in working on species in the South are thus obliged to connect themselves with the North and this is costly. We therefore have to ensure that the South has access to these databases that, after all, directly concern the South.

\section{Kay Raseroka}

Thank you very much. We have run out of time and I apologise to those participants who have not had the opportunity of speaking. 